\title{
International Experience of Liberalisation and Evolution of Natural Gas Markets
}

During the liberalisation of their natural gas markets, the United States and the United Kingdom both underwent a reform process that involved a transition from government supervision and gradual deregulation. This provides valuable experience to draw on in various areas, including natural gas exploration and development, storage and transportation, pricing mechanisms, market trading and institutional guarantees.

\subsection{Incentivising New Entrants and Establishing Competitive Natural Gas Markets}

From comparisons of the state of development of the natural gas markets of six countries and regions, it can be deduced that a competitive natural gas market requires the involvement of entities of a certain size (Table 12.1). The United States and Britain are the most typical competitive markets, and reflect the involvement of, and high levels of competition between, a multitude of different entities in many areas of the market, including exploration and extraction, storage and transportation, wholesale and retail, and trading

\footnotetext{
* This chapter was overseen by Xiaoming Wang from the Development Research Center of the State Council and Mallika Ishwaran from Shell International. It was jointly completed by Yusong Deng, Jiaofeng Guo, Shouhai Chen from China University of Petroleum and Qingle Wu from Shell China. Other members of the topic group participated in discussions and revisions.
}

centres. By comparison, in China, Japan and South Korea there is a lack of competition; upstream and midstream business is mainly monopolised by oligarchs and there has been no division of production, storage, transportation or sales operations.

A competitive, reactive and fluid natural gas market should have the following characteristics:

- a greater number of entities, allowing competition in the upstream and midstream market sectors to provide diversified services to consumers, for which funds can be raised from investors;

- competitive prices at both the wholesale and retail levels;

- non-discriminatory access to pipelines, gas storage, LNG receiving stations and other similar infrastructure.

\subsection{Opening the Upstream Sector to Competition}

Availability of resources is a precondition of natural gas usage, so, looking at the natural gas industry as a whole, upstream production departments have virtual control over the operation of the whole industrial chain and the distribution of returns. As a result, opening up upstream exploration and development to new entrants is of major importance to the development of the natural gas market. 
Table 12.1 Main characteristics of natural gas markets of various countries and regions

\begin{tabular}{|c|c|c|c|c|c|c|c|}
\hline Natural gas index & Type & USA & $\mathrm{EU}$ & UK & Japan & $\begin{array}{l}\text { S. } \\
\text { Korea }\end{array}$ & China \\
\hline \multirow[t]{2}{*}{ Supply (bcm/year) } & $\begin{array}{l}\text { Domestic } \\
\text { production }\end{array}$ & 689 & 269 & 38 & 3 & 0.5 & 115 \\
\hline & Net imports & 37 & 231 & 39 & 123 & 53 & 49 \\
\hline \multirow{2}{*}{$\begin{array}{l}\text { Consumption } \\
\text { (percentage of total by } \\
\text { sector \%) }\end{array}$} & Power & 40 & 30 & 30 & 65 & 50 & 15 \\
\hline & Industry & 20 & 20 & 10 & 5 & 20 & 45 \\
\hline Transport pipelines (km) & & $500 \mathrm{k}$ & $200 \mathrm{k}$ & $8 \mathrm{k}$ & $5 \mathrm{k}$ & $4 \mathrm{k}$ & $50 \mathrm{k}$ \\
\hline Wholesale competition & & $\checkmark$ & $\begin{array}{l}\text { Limited } \\
\text { (oligarchic } \\
\text { monopoly) }\end{array}$ & $\checkmark$ & $\begin{array}{l}\text { Limited } \\
\text { (oligarchic } \\
\text { monopoly) }\end{array}$ & $\mathrm{X}$ & $\mathrm{X}$ \\
\hline \multirow[t]{3}{*}{ Open access } & Upstream & $\checkmark$ & $\checkmark$ & $\checkmark$ & $\checkmark$ & $X$ & $\mathrm{X}$ \\
\hline & Transportation & $\checkmark$ & $\checkmark$ & $\checkmark$ & $\checkmark$ & $X$ & $\mathrm{X}$ \\
\hline & Distribution & Diversified & Diversified & $\checkmark$ & $\mathrm{X}$ & $X$ & $\mathrm{X}$ \\
\hline \multicolumn{2}{|c|}{$\begin{array}{l}\text { Division of ownership of transportation } \\
\text { and sales }\end{array}$} & $\checkmark$ & Diversified & $\checkmark$ & $X$ & $\mathrm{X}$ & $\mathrm{X}$ \\
\hline \multicolumn{2}{|c|}{ Independent (federal) market rights } & $\checkmark$ & $\checkmark$ & $\checkmark$ & $\mathrm{X}$ & $X$ & $\mathrm{X}$ \\
\hline \multicolumn{2}{|l|}{ Fluid market centre } & $\checkmark$ & $\checkmark$ & $\checkmark$ & $X$ & $X$ & $\mathrm{X}$ \\
\hline
\end{tabular}

Note Data is for 2013 (except natural gas consumption levels for China, which are based on 2011 data from power generation and industrial departments)

Source Vivid Economics, based on IEA, EIA, Chinese Government and ENTSOG data

In developed European countries and in the United States, the natural gas exploration and development field is for the most part a competitive market, and this is closely related to the system of access to mineral rights. For instance, the privatisation of land ownership (and resources that lie beneath it) has been effective in encouraging exploration and development of natural gas, while also creating the conditions necessary for the shale natural gas revolution. The approach adopted in The Netherlands of "50-50 state-private ownership" has acted as a major stimulus in encouraging exploration for natural gas resources. The government generally implements a system of business licences, including mineral rights release mechanisms, for any companies that have been awarded mineral rights, thus avoiding hoarding of rights and delayed development. In the UK, for example, companies involved in bidding for mineral rights are expected to strictly abide by exploration and development requirements, otherwise they are likely to lose their licences. However, such a system requires strict supervision by the regulatory body.

However, natural gas resources differ from the average commodity in that not only do they have a value as a raw material, but access to such resources is also accompanied by massive profits and, in addition, they have a strategic value that derives from their relatively large influence on the national economy as a whole. It is due to such factors that in recent years, resource holders such as Russia and Middle Eastern and South American countries have been exerting evertighter control over their oil and gas resources. In light of this, the problem of how to increase activity in the upstream exploration and development field, while also ensuring that the majority of profits remain within the country, in addition to ensuring greater energy security for China, deserves greater consideration. 


\subsection{Orderly and Gradual Implementation of Pipeline Access Policies}

Between the 1980s and the present day, policy regarding the regulation of natural gas pipelines has been reformed in both the United States and the European Union, resulting in the creation of an independent, open natural gas transportation system. The increased level of supervision over the operation of natural gas pipeline networks (i.e. the aspects that usually attract natural monopolies) has ensured pipeline and network interconnectivity and access to services for third parties. The process by which this was achieved in general consisted of three stages.

In the first stage, pipelines were encouraged to provide transportation services to third parties, while government regulation was strengthened. This stage may be seen as a period of preparatory work for the encouragement of third-party access. However, governments do not force oil companies to provide non-discriminatory services in terms of access to their pipelines; incentives are provided to companies that provide access, and at the same time the gas end user is allowed to sign contracts directly with producers. This procedure allows feasibility to be examined and enables the discovery of any problems that may exist in implementing third-party access to pipelines. At the same time, during this stage, the government continues to enhance its supervisory capabilities, with the gradual creation of an independent, unified, impartial and effective natural gas industry regulatory framework. This is in fact preparatory work that will allow the reform of supervisory capabilities and the formation of the teams necessary to carry this out.

In the second stage, pipeline third-party access is enforced. This effectively eliminates the bundling of natural gas sales and pipeline transport. The government issues the relevant regulations that make it obligatory for natural gas infrastructure operators to provide fair and just access to pipeline transport, gas storage, gasification, liquefaction and compression services to all users.

In the third stage, independence of pipeline transportation services is encouraged. The natural gas pipeline businesses of upstream/midstream/ downstream integrated companies are split from them, creating a number of independent pipeline companies, after which creation of the oil and

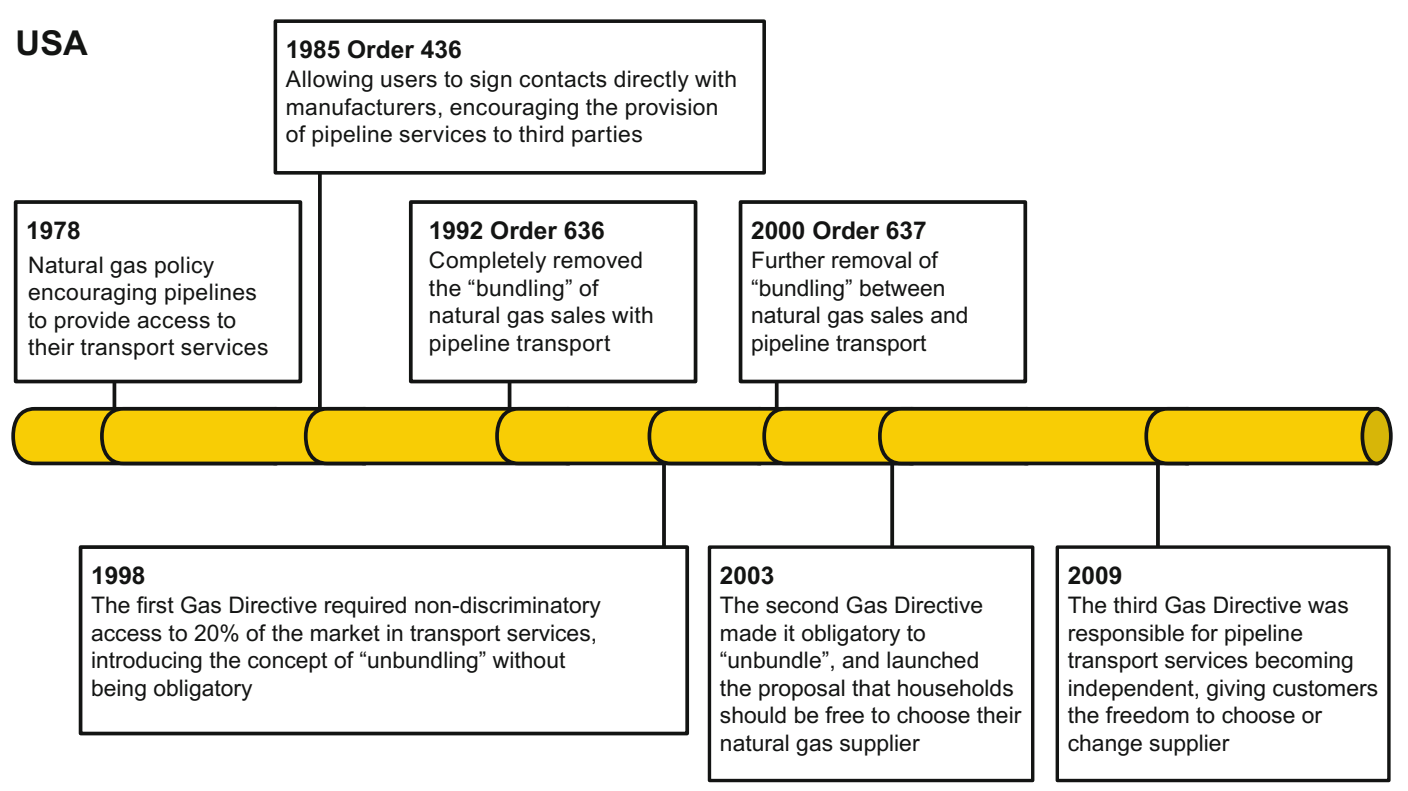

\section{EUROPE}

Fig. 12.1 Timeline of development of pipeline regulatory policy in the United States and Europe 
natural gas pipeline supervisory system can be completed (Fig. 12.1).

Analysis of experience in the United States indicates that, from start to finish, reform of pipeline policy took more than 20 years, while in the EU the process has taken 10 years, so clearly this is a fairly slow process and cannot be achieved overnight. Moreover, pipeline reform in both the US and the EU involved a process of encouraging third-party access, followed by obligatory access, which was then followed by the splitting up of upstream/midstream businesses. This is the pattern of reform best suited to the natural gas industry, and deserves further study and emulation.

\section{The development of US natural gas pipeline regulatory policy}

In terms of structure, the structure of the early natural gas industry in the United States was similar to that encountered today in China: producers sold natural gas to pipeline transportation companies, and pipeline transportation companies then sold the natural gas to local distribution companies, with the natural gas being sold to the end user by the local distribution company. The natural gas sales price was controlled by federal government, and the price of natural gas sold to the end user by the local distribution company was controlled by local government institutions. The administration had virtual control over all parts of the natural gas industry, and the state was not only responsible for supervision of the naturally monopolistic pipeline transportation sector, but also for the competitive sectors of the natural gas industry (such as production and wholesale supplies). The strict regulation by the state resulted not only in natural gas companies being placed under a great deal of pressure, but also in abnormal development in terms of natural gas prices and consumption. The excessive regulation of natural gas producers led to the gas supply shortages encountered in the United States in the 1970s.

In order to remove the monopolies that had resulted from closed-type industrial operations, and to encourage and co-ordinate development in the natural gas industry, the United States government began to adjust its policies towards natural gas industry regulation, and as a result natural gas pipeline regulatory policy underwent four main rounds of revision. In 1978, the Natural Gas Policy Act (NGPA) introduced a staggered process for relaxation of natural gas wellhead pricing controls, at the same time as encouraging pipelines to open up access to their transport services. In 1985, the Federal Energy Regulatory Commission (FERC) issued Order 436, which put pressure on pipeline transport companies of different states to separate sales and transport functions, while introducing competition mechanisms that gave natural gas end users and manufacturers more freedom of choice. In 1992, FERC issued order 636, which required state pipeline companies to separate natural gas sales from pipeline transport and establish separate companies to handle sales. By adopting pipeline usage rights, this order eliminated the widespread unfair competition largely associated with the supply of natural gas by state pipeline companies. It also introduced procedures whereby contracted transport could be sold on, allowing a "firm shipper" (any user of pipeline transport) to buy transport capacity from another firm shipper with excess transport capacity. In 2000, FERC then issued order 637, which went further, completing the unbundling of gas supplies and transport services.

\section{The development of European natural gas pipeline regulatory policy}

Europe is one of the three main global natural gas-consuming regions, and in the last 40 years, natural gas's share of overall energy consumption has continued to grow. At the same time, the business modes and regulatory systems applied to 
the natural gas industry in Europe have undergone continual adjustment. The natural gas industry regulatory systems and policies of each individual member country of the European Union are established with reference to "directives" provided by the European Union. If one looks at the development of the European natural gas industry over the last 10 years, the European Union issued three main directives, and a major component of these relates to encouraging the market liberalisation of natural gas pipelines.

In 1998, The EU issued the First Gas Directive, providing the impetus for the acceleration of the liberalisation of the internal European natural gas market. This directive proposed that in order to ensure the establishment and efficient operation of a European internal natural gas market, each country within the EU had a duty to ensure fair competition in terms of transport, storage and distribution, while requiring that all members should complete revision of their legislation within two years of the directive taking force. In terms of pipeline policy, the directive recommended the opening of a $20 \%$ non-discriminatory market access, with the introduction of the concept of "unbundling", without it being obligatory.

In 2003, the EU issued the Second Gas Directive, which required that all member states adhere to the regulations concerning the single market and adjust their own statutes, requiring that the natural gas market be opened to the non-residential users of all European countries before July 2004. Integrated companies had to complete the legal dismantling of their pipeline and marketing businesses, followed by the opening of natural gas markets to all users before July 2007, finally achieving the aim of allowing the consumer freedom of choice of gas supplier. Regarding pipeline policy, the enforcement of regulations relating to unbundling resulted in households being given the right to freely choose their natural gas supplier.
In 2009, the EU issued the Third Internal Energy Market Package (also known as the Third Package), which brought into force EU energy industry reforms. Based on these new reforms, large power and gas companies had to select one of the following three reform schemes:

- ownership unbundling, which requires companies to sell their distribution network, thus completing the separation of the manufacturer from the network;

- unbundling of business operations, which, while allowing retention of ownership of distribution networks, required the establishment of an independent company (known as an "independent system operator") who would be responsible for the operation of the gas distribution network;

- unbundling of managerial responsibility, allowing the ownership and management of gas distribution networks but requiring a subsidiary to manage the gas distribution network and entailed ensuring managerial and policy-making autonomy (known as an "independent transmission operator").

These reforms also required that each country establish an independent regulator, responsible for ensuring that large energy companies actually implemented this "division of production and supply" and for ensuring that the rules that apply to free competition in energy markets were put into play.

\subsection{Third-Party Access: The First Step to Infrastructure Reform}

In the natural gas industrial chain, upstream production and downstream sales are both sectors to which natural monopolies do not apply, and as such, efficiency can be improved by the introduction of market competition. Operation of 
midstream assets such as pipelines, on the other hand, exhibits the characteristics of a natural monopoly, with high fixed-cost investment and relatively low operational and management charges. There is thus a rationale for operation of pipeline services by a single company being the most effective approach to operation. This in turn is effective in reducing the overall operational cost to society. The special characteristics of midstream asset natural monopolies are one of the reasons that they are not exposed to the pressures of market competition, and to some extent they also dominate the markets. As a result of this, we recommend that greater regulation of midstream pipeline assets is required, to prevent companies that occupy a position that can be considered a "natural monopoly" from abusing their power to influence markets and extract ever-higher levels of monopolistic profits.

Generally, supervision of midstream assets consists of a number of approaches: regulation of fee standards applied to pipeline transportation and other such infrastructure, implementation of infrastructure third-party access and division of ownership. In order to prevent monopolistic enterprises extracting extremely high monopolistic fees for midstream services, the government needs to investigate actual operating costs and reasonable profit levels in order to establish reasonable charging standards. Apart from this, independent owners of midstream assets may also take advantage of their market dominance to increase pipeline transportation costs or restrict natural gas transportation, and this in itself is also responsible for reduced upstream and downstream competition, while also reducing pipeline usage. To prevent owners with natural monopolies over infrastructure taking advantage of their market position, and to ensure that all other parties have fair access to usage of pipelines and other infrastructure, the government is generally required to exert a supervisory influence, and this is exactly what is being referred to as the third-party access (TPA) regime.

International experience has demonstrated that third-party access policies balance out the economic interests of the owners of midstream pipelines and upstream and downstream production and consumption. This is not only beneficial in that it allows full use to be made of the potential of such infrastructure, but also in terms of attracting capital investment into the infrastructure construction sector

Regulatory policy and its effects in the UK provide excellent proof of this. Between the 1960s and the 1980s, when the North Sea oil fields were being developed on a significant scale, the production and transportation of British gas was led by only a few major companies. However, as the yield of these oil and gas fields has dropped, large companies have begun to find it hard to obtain satisfactory benefits, while receiving stations and pipelines have redundant capacity. At the same time, many small enterprises have entered the upstream field, developing small-scale oil and gas fields, using the pipelines of the larger companies to transport their oil and gas products. There is a lack of legal framework, and thus the potential exists for disputes to occur between the owners of infrastructure and the owners of oil and gas fields. Indeed, throughout the 1990s there was a worry that the cost of usage of infrastructure was becoming too high in relation to the costs and risks associated with the development of small oil and gas fields.

In order to resolve this situation, between the 1990s and the early 21st century, the British energy regulator (or the Department of Energy and Climate Change as it is now known) established a new access negotiation procedure, accompanied by a raft of legal and regulatory measures that reduced stakeholders' uncertainties at the same time as providing a regulatory framework with a legal basis and arbitration mechanisms that became a foundation via which negotiations could be completed in a manner that benefited both stakeholders. With the gradual appearance and introduction of this legal and regulatory framework, the natural gas markets were able to develop further, which benefited all the stakeholders concerned. This allowed smaller enterprises to enter the larger oil and gas exploration market, which in turn offered further 
benefits to the owners of infrastructure, reducing the cost of redundant infrastructure, while the government also benefited in terms of reduced unemployment and an increase in tax revenues.

A well-designed third-party pipeline access policy and regulatory framework should satisfy the following conditions:

- the policy should be effective, with the regulator being responsible for drafting and implementing policies relating to duties and standards;

- appropriate pricing, with the regulator providing a framework, allowing investors and users to reach agreement on pricing in terms of TPA and appropriate returns mechanisms;

- risk avoidance, requiring the regulatory framework to be stable and reliable, in a way that reduces the risks to the investor and the user to the minimum.

Third-party access policy frameworks will affect different types of natural gas markets in different ways. For instance, Japan is a typical natural gas importer, being incapable of achieving competition between upstream manufacturers, therefore TPA policy is limited. However, where China with its continuously growing markets is concerned, a regulatory framework offers significant benefits, providing a stimulus for investment in the midstream field.

\subsection{Unbundling: An Important Element of Liberalisation of Natural Gas Markets}

As mentioned previously, regulation that applies to the midstream sector generally involves approaches such as pricing standards applied being to infrastructure such as transport pipelines, the implementation of third-party access to such infrastructure and the unbundling or partitioning of ownership. In practice, even when the government establishes the principles of third-party access, monopolistic companies still have many methods of ostracising third parties, for instance by a lack of transparency regarding available pipeline transport capacity or pricing, or by contractual obligations such as conducting obligatory technical research etc. Strict application of the principles of third-party access can suppress these anti-competitive market forces to some degree.

However, some experts are of the opinion that unbundling is a more effective approach to resolving such issues. Unbundling involves separating the factors that motivate operators at the midstream stage from those that motivate operators at the upstream and downstream stages, which reduces the likelihood of anti-competitive activities. Unbundling is not the actual objective, though; it is just an effective method of ensuring the feasibility of third-party access. Whether or not open access measures eventually result in an efficient actively competitive natural gas market is the final proof of whether mechanisms for unbundling have been successful or not. For instance, one of the benefits of unbundling is the additional upstream activity resulting from competition, encouraging greater manufacturing efficiency and expansion.

Where nations that have a domestic production capability are concerned, the earlier unbundling takes place and the more completely it occurs, the more effective it will be. Looking at the UK and The Netherlands and their domestic North Sea resources, and comparing them to nations such as France and Germany that have only limited domestic resources, unbundling occurred more rapidly. In the case of Japan, which has only minimal natural gas resources, only tentative unbundling occurred. In juxtaposition to this is the United States. The US has plentiful upstream resources, with a wide distribution. In fact, unbundling commenced in the US at a very early stage; in 1992 the United States had already required the introduction of legislation and other structural unbundling measures. One has to be cautious about making generalisations in the analysis of the factors that motivated this, but where nations that possess domestic resources 
were concerned, unbundling resulted in greater economic benefits, and this in turn has led to such nations being more willing to institute such reforms.

The unbundling process is of great importance, and depending on the extent to which unbundling takes place, it can be split into five categories: service unbundling, financial unbundling, legal unbundling, structural unbundling and unbundling of ownership. Unbundling at a higher level lays the foundations for unbundling at a lower level, lower-level unbundling being simply an extension of the unbundling occurring at higher levels. A good example of this is that financial unbundling must be implemented at the same time as service unbundling, and so on; the most thorough form of unbundling is ownership unbundling (see Table 12.2).

Analysis of midstream asset unbundling case histories from the United States and Europe indicates that, if regulators are given sufficient powers by the state, it is unnecessary to implement complete ownership unbundling. Among the nations analysed, only the UK and The Netherlands instigated complete ownership unbundling, while France and Germany carried out structural unbundling and never attempted complete ownership unbundling. Experiences in the US also demonstrated that, by applying a strict model to the operations of natural gas transport companies, it became unnecessary to apply ownership unbundling in order to ensure effective competition in the natural gas market. To summarise, the majority of the nations mentioned above instigated structural unbundling, without the need to carry out complete ownership unbundling. From this one may conclude that simply carrying out structural unbundling in conjunction with strict regulation provided the best results.

In contrast to pipelines, implementation of unbundling applied to infrastructure such as LNG receiving stations and peak gas storage installations has not been so strict. The reason for this is that, generally speaking, there is a large number of natural gas receiving stations and peak gas storage installations, therefore there is more opportunity for competition to arise; when compared to LNG receiving stations and peak gas storage installations, natural gas pipelines exhibit more pronounced natural monopoly characteristics. Where a pipeline network is connected to a fairly well developed market, LNG receiving stations take on the characteristics of supply resources, competition occurring with other receiving stations thus restricting market dominance. In a similar manner, in a diversified market with dense connections there will be many storage providers, while pipeline storage capacity, flexible natural gas production capacity and dynamic increase and decrease in demand can also be considered as providing storage services. In light of this, unbundling and third-party access policy should take this into account and treat such installations with more leniency.

\subsection{Natural Gas Pricing Reform as Part of the Market Liberalisation and Development Process}

Due to different natural gas markets having developed to differing degrees, there are three types of main pricing mechanism found in the main global importers of natural gas: the first type relies completely on market-driven prices, such as is encountered in the US and the UK. Here we have relatively mature natural gas markets, and a completely unregulated natural gas price, determined by market demand and supply; however, third-party access to pipelines is obligatory, resulting in a market where competition occurs directly between different gas companies. The NYMEX Henry Hub and the UK's NBP trading prices act as the reference prices for North American and European trading.

The second category is reliance on the netback pricing method, such as is adopted in European countries other than the UK. Market 

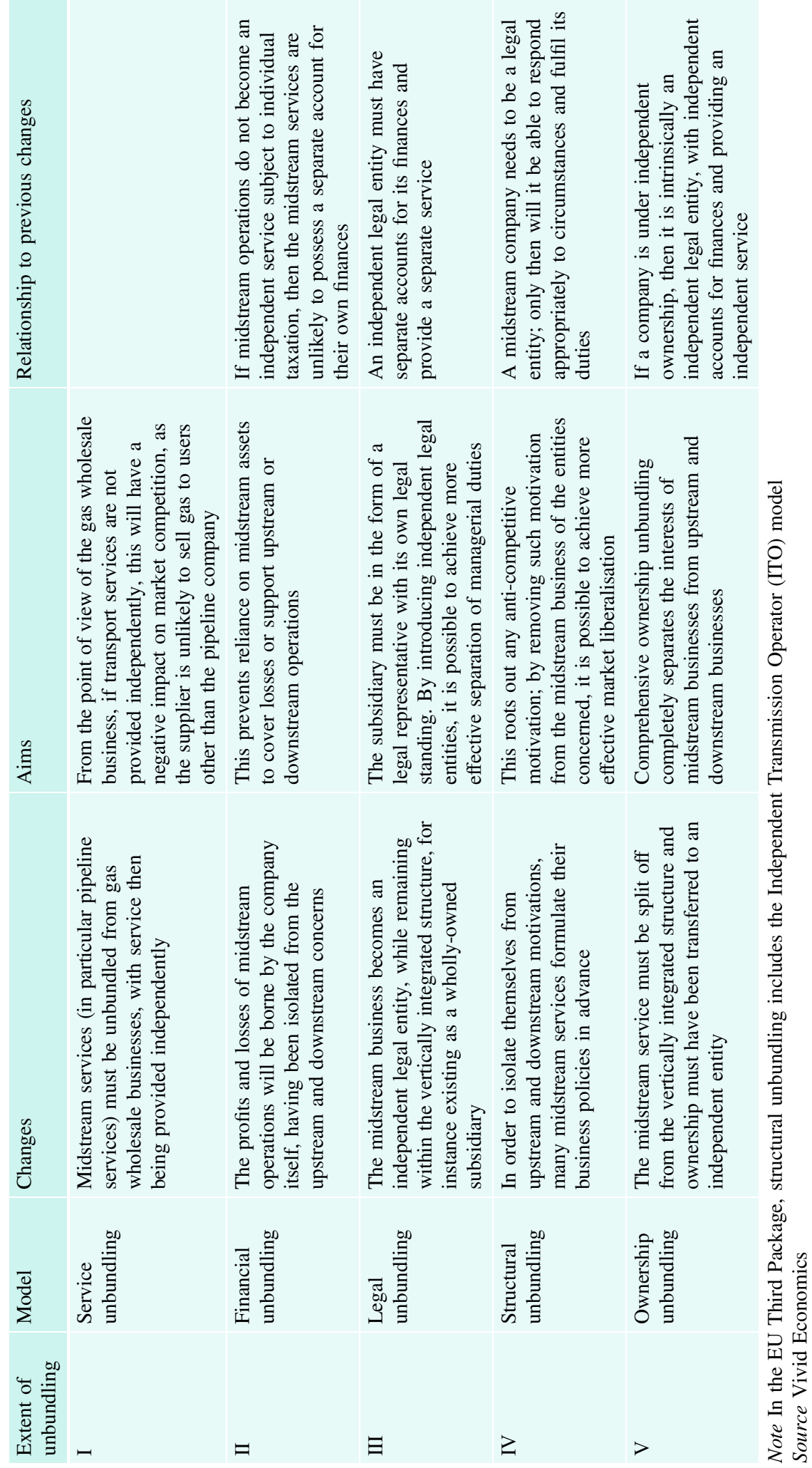
netback pricing is based on the market value of energy sources which are an alternative fuel to natural gas; this employs retrospective methods, involving deduction of transport, storage, distribution and other such costs to determine an upstream price. When compared to the US and UK markets, the European market is still in the stage of transition to full market competition. Natural gas consumption relies mainly on external imports, and most natural gas is traded in long-term contracts. The price is mainly pegged against oil products, but there is a certain amount of lag in the adjustment in contract prices.

The third type mainly relies on pegging against the price of imported oil, examples of which are Japan and South Korea. The development of the natural gas markets in both Japan and Korea have been somewhat delayed, with reliance mainly being on imports. At the same time, since there is a lack of a representative trading centre, there is little choice but to peg natural gas prices against crude oil. For instance, Japan's Chubu Electric Power agreed a pricing formula with the Qatar Gas Transport Company in 2001 which stated: $\mathrm{P}=0.1485 \times \mathrm{JCC}+$ $0.08675+\mathrm{S}$. Here, $\mathrm{S}$ is an adjustment figure, which was used to moderate the effects of the violent fluctuation in the international oil price. Prior to 2005, the international oil price was relatively low, with the price of gas imported by Japan and South Korea being more or less the same as in Europe and the United States. In recent years, with further fluctuations in the international oil price, an "Asian Premium" phenomenon has arisen, with a major increase in the cost of gas use.

Reform of pricing mechanisms is a gradual process, with the final objective being a pricing mechanism which achieves completely open-market competition between different gas companies. If you take the historical situation in the US, the government controlled natural gas prices, applying a "cost plus" method to import prices, with the federal government controlling long-distance transport pipeline pricing and local government organisations being responsible for the price paid by the final user. Governmental pricing regulation resulted in the price remaining relatively low over a long period of time, which led in turn to problems of supply being unable to satisfy demand. Subsequently, the government eased controls over the price of imported natural gas, and the creation of a trading centre allowed the gradual evolution of open-market pricing regulation. Historically, the reform of pricing mechanisms in the UK was similar to that of the US, involving a transition from prices being set by the government to prices being set by markets. Subsequently we find that the pricing regulation that was applied to these markets resulted in trading centres adopting pricing based on a reference market price model.

\subsection{The Role of Natural Gas Trading Markets}

Currently, global gas trading relies mainly on long-term contracts, and this plays a major role in balancing upstream and downstream interests and stabilising the relationship between supply and demand. Long-term contracts allow natural gas to be linked to the prices of alternative fuels, market trading prices and many other indices, thereby ensuring that upstream investors receive a stable return over a number of decades and protecting investment in exploration and production. This is particularly beneficial for stabilisation of upstream investment. Relative to long-term contracts, spot trading is more flexible and fluid and is taking on an ever-greater role in natural gas trading. Taking shale natural gas in the US as an example, due to uncertainties over yields, shale natural gas developers are unable to obtain long-term contracts on favourable terms and therefore the development of shale natural gas relies heavily on the spot trading market.

More important, though, is the fact that the creation of spot trading markets has provided a new pricing method for natural gas market liberalisation, which has also accelerated the creation and growth of trading centres. Take, for instance, US FERC order 636 in 1992, which made it obligatory for pipeline companies to provide access to their services, an event that resulted in a substantial loosening of regulation 
over gas markets, and a market competitionbased pricing mechanism replacing the previous pricing model, a government-driven pricing mechanism. At the same time, FERC began to promote the concept of natural gas market trading centres, adopting the stance that natural gas market trading centres should be responsible for providing natural gas supplies, transport, storage, deployment, enhanced administration and other such services or combinations of services to the customers of pipeline transport operators. As a result, 36 internal natural gas market trading centres were created, covering all the US natural gas pipeline networks between 1993 and 1998. By 2003, 13 of these natural gas trading centres were closed down, either due to their trading base being insufficient, resulting in small trading volumes, or because they lacked competitiveness. Currently, there are a total of 24 natural gas trading centres, mostly in Texas and Louisiana, which provide hub services to the natural gas markets. The appearance of these natural gas trading centres accelerated the formulation and systematisation of open-market natural gas pricing mechanisms, streamlining the allocation of resources within the gas markets, increasing market efficiency and enriching the choice of investments available to those involved in these markets. This evolution also helped the US to establish itself as a leader in terms of energy pricing, as well as ensuring US national energy security.

Natural gas trading centres clearly offer both benefits and drawbacks. They have two major effects. The first is that there is a physical connection between the buyer and the seller, the second is that pricing is set based on market competition. As a result of this, allowing markets to provide pricing signals increases economic efficiency in terms of trading and investment decision-making, in addition to resulting in a relative drop in trading costs, giving greater returns to those investing in such markets. In addition, natural gas trading centres are able to balance problems in supply and demand due to their pricing mechanisms, thereby ensuring the security of natural gas supplies. A potential drawback is their impact on current market models. With pricing being determined by competition between different parties, rather than by the government or other leading influences within the market, it is possible that they can cause greater fluctuations in pricing in the short term.

From the global experience already gained by the main countries operating natural gas hub trading centres, we can conclude that, in light of the different functioning of natural gas trading centres, the success or otherwise of natural gas trading centres depends on three preconditions (see Table 12.3):

Table 12.3 Conditions for creation of a natural gas trading centre

\begin{tabular}{|l|l|l|}
$\begin{array}{l}\text { Basic } \\
\text { infrastructure } \\
\text { conditions }\end{array}$ & $\begin{array}{l}\text { A complete and open natural } \\
\text { gas distribution network }\end{array}$ & $\begin{array}{l}\text { Connections to both domestic and overseas gas-consuming } \\
\text { and supplying enterprises in an open channel gas } \\
\text { distribution network }\end{array}$ \\
\hline $\begin{array}{l}\text { Market } \\
\text { conditions }\end{array}$ & $\begin{array}{l}\text { A large number of different } \\
\text { participants within the market } \\
\text { Relatively low level of market } \\
\text { concentration }\end{array}$ & $\begin{array}{l}\text { There must be sufficient numbers of entities within the } \\
\text { market, including both buyers and sellers }\end{array}$ \\
\hline $\begin{array}{l}\text { Formalised trading activities } \\
\text { There should not be dominant suppliers or consumers }\end{array}$ & $\begin{array}{l}\text { Natural gas trading and pipeline transport prices should be } \\
\text { regulated by the government, with fair and reasonable } \\
\text { prices; traded gas quantities should be able to enter pipelines } \\
\text { freely; market prices should be made public and transparent } \\
\text { The wholesale trading price of gas along the supply chain } \\
\text { should be determined freely by the market }\end{array}$ \\
\hline Market liberalisation of prices \\
\hline conditions
\end{tabular}


- a natural gas transport network which is completely open to access, which is available for the use of market participants on a non-discriminatory basis;

- large numbers of independent buyers and sellers actively involved in arbitrage, none of whom possess the capability to dominate the market;

- government support for the opening of its natural gas wholesale markets accompanied by stable, transparent and reliable rules and regulations.

Trading centres also require enterprises to engage in trades based on arbitrage, which will improve market operating efficiencies, and arbitrage activities rely on the accuracy and high transparency of reports of natural gas prices.

By carrying out extensive natural gas sector reforms, China will possess the conditions that would allow it to become the premier natural gas trading centre in Asia. Looking at China's advantages, its natural gas output, the extent of development of its gas transportation pipelines, the scale of its LNG imports and the significance of its position in the Asian energy market are all clear. However, China's natural gas distribution network is not well developed, the market is still relatively concentrated, third-party access mechanisms are ineffective and pricing is still subject to government control, all of which are factors that are restricting the creation of a natural gas trading centre in China.

Experience gained in the United States and Europe since the 1990s in the creation and development of natural gas trading markets provides a valuable reference for China. The first thing to note is the extent to which the creation of a natural gas market will have a major effect on the development of trading centres. The development of natural gas hubs in Europe only started in 2008, and for a period of time they were not that successful, due to the slowness of market liberalisation in the European natural gas markets.
Second, government restrictions over trading activities can also have a major influence on trading centre development. Benefiting from the enormous supplies of the Groningen gas field, and recent increases in the number of LNG receiving stations and increased storage facilities, the Dutch Title Transfer Facility (TTF) is widely recognised as being the most successful European continental natural gas hub, and contract volumes indicated that by 2013/2014 TTF had already surpassed NBP to become the largest European fluidity hub (Natural Gas Daily 2014). Zeebrugge (Belgium), on the other hand, is viewed as the least successful example, due to its low level of trading activity, even to the extent that it is no longer viewed as a hub. Zeebrugge possesses suitable geographic conditions for it to become a natural gas hub, but commercial restrictions imposed by the local government have restricted the number of participants involved, reducing the trading platform's rate of growth.

Third, government impetus is capable of having a substantial effect in the short term. In the early 1990s, the United States had already achieved market liberalisation of its natural gas prices, but the link between natural gas prices of different regions (eastern region and western region) showed only a weak correlation. At the end of the 1990s, as the United States government promoted the adoption of the "law of one price" across the whole of the US natural gas market, after subtraction of transportation costs, a single transregional price was applied, at which stage price correlation had already developed to a very high degree (Cuddington and Wang 2006; Doane and Spulber 1994).

Fourth, formalised and orderly trading mechanisms also have a beneficial effect in encouraging the development of natural gas trading centres. Taking the development of the NBP in the UK as an example, the Uniform Network Code has played a crucial role. The Uniform Network Code provided the regulations and procedures for supervision of third-party 
(TRA) use of the UK natural gas network. This introduced a daily balance system and short-term natural gas trading and one of the standardised contracts (NBP97) became the cornerstone of the UK direct trading contract.

Based on the experience gained in the development of natural gas trading centres in the United States and European Countries, and in light of the specific characteristics of China's natural gas industry, development of China's natural gas trading centres requires a 5- to 10 -year plan to be drawn up. Trial trading centres should be established first. The government could establish natural gas pipeline networks to which third-party access applies in individual regions such as Shanghai, with the introduction of transparent natural gas pricing mechanisms. This would create the conditions for competition in natural gas demand and supply. Then, after conditions have developed over a certain period of time, a real-time gross settlement system should be introduced to trial trading centres. On the basis of this, the government can extend the areas covered by trials further, or increase the number of categories of buyers and sellers, at the same time as making further enhancements to market regulation. As the effects of these trials become more noticeable, they will attract the participation of greater numbers of producers and consumers in market trading. Once the price of natural gas in trading trials is less than the price of natural gas for traditional contracts, the number of traditional contracts traded by consumers will drop and further interest in purchasing natural gas from trial trading centres will develop. On the other hand, when the price of natural gas traded by trial trading centres is higher than that of traditional natural gas contracts, suppliers will be more willing to supply gas to these trial centres, thus also reducing the numbers of traditional contracts traded. As more and more diverse participants become involved in trading in these trial centres, the benefits of trading will increase, due to the network effect mentioned above. Hub-based pricing will be applied on an increasing scale and over a greater range, until partial market liberalisation is achieved or geographical limits become a factor.

\subsection{Establishment of an Independent and Legally Protected Regulatory System}

Major state regulatory bodies generally include an overall energy administration and an energy regulator, with powers being divided between these two bodies. The overall energy administration is mainly responsible for establishing energy strategy, planning and policy, playing a role in the balancing of total energy resources, with responsibility for energy security, modification of energy structures, promotion of energy saving and energy efficiency administration, collation and analysis of data, scientific innovation in relation to energy and international energy co-operation. It is also responsible for harmonising activities in conjunction with related departments. The energy regulator, on the other hand, is mainly responsible for ensuring order within energy markets, while promoting market competition within the industry and resolving disputes. It is also responsible for regulation of sectors in which natural monopolies exist, thus protecting the overall interests of the market participants. The overall energy administration is responsible for establishing policy; the energy regulator is responsible for implementing it (see Table 12.4).

These two bodies may be partially independent or completely separate from each other, and from the point of view of energy management they ideally act as a counterbalance to each other, which satisfies the requirements of modern administrative systems by separating the three powers of regulation-making, implementation and supervision. The regulator should be independent in terms of powers and positioning, to ensure that it is capable of reaching appropriate decisions which treat all market participants equally. Take the US Federal Energy Regulatory Commission (FERC) as an example. This is an 

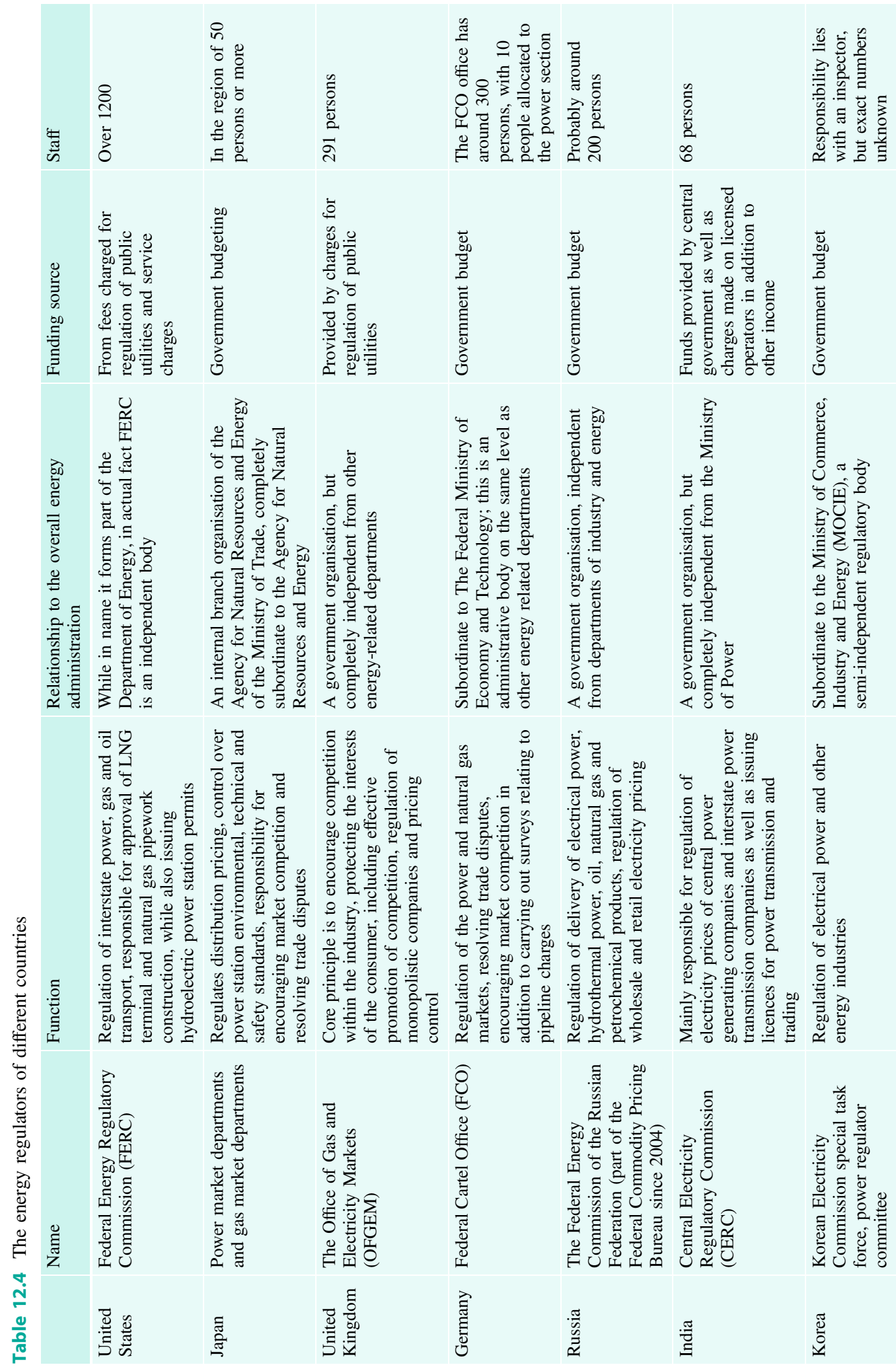
independent administrative body which is subordinate to the US government. It is responsible for the regulation of business activities involving gas, electrical power, hydroelectric power and oil, covering pipelines and distribution links; and policy-making and the resolution of disputes require a majority vote of the five committee members. There are five committee members, one of whom is the chair of the committee, and the names of whom are suggested by the President and ratified by the Senate (though not more than three fifths of the committee members may come from one political party). Policy decisions are issued by a court of law, and not by the United States Congress, and when cases are being heard, no private discussions are permitted.

The main regulatory role of FERC is to prevent companies from taking advantage of their monopolistic position, with the aims of the regulation including:

- prevention of discriminatory or preferential treatment;

- prevention of inefficient manufacturing and unfair pricing practices;

- ensuring excellence of service;

- prevention of infrastructure redundancy and wastage;

- where competition does not exist or is not able to exist, acting as an agent for the promotion of competition;

- promotion of safe, high-quality, environmentally friendly energy infrastructure via implementation of consistent policies;

- where possible, encouraging overall market competition in place of traditional regulation.

From the point of view of the natural gas industry, the main function of the Commission relates to pricing controls, interpretation of the relevant legal statues and service regulation, and the scope of regulation includes roughly 120 interstate gas pipelines. At the same time, the Commission has the power to authorise the construction and siting of gas delivery-related infrastructure as well as being responsible for the evaluation of the environmental impact that this may cause.

\subsection{A Roadmap for Natural Gas Market Reform}

Reform of market structures and the administrative regime applied to natural gas is a gradual process. Looking at the timeline of developments in the US natural gas market, this process involved a progression from complete government regulation and the government setting of prices to a situation where pricing controls were gradually withdrawn and bundling of gas sales was eliminated, followed by a fully developed natural gas market with pricing determined by the market itself (see Fig. 12.2).

The reform of the natural gas market is a long-term and difficult process, requiring a particular political environment, relevant infrastructure and associated government policy. Favourable political and market climates encouraged the reform of both the British and American natural gas markets. For instance, looking at the period from the 1970s to the 1980s, the oil crisis resulted in massive pressure being put on the government to introduce market reforms, while the extensive pipeline network infrastructure was also a driving force behind the natural gas market reforms in the US. In the UK, the Conservative party, which was in power at that time, under the leadership of Margaret Thatcher, was in the midst of carrying out privatisation of publicly owned industries, including vertically integrated power and gas companies, in order to relieve the financial problems faced by the government at that time; this also created political and market conditions favourable to market reform. In contrast to this, if reforms do not proceed effectively, there is also the possibility that they will fail. In the last 20 years, South Korea has encountered many difficulties in the reform of its natural gas market, in particular relating to the powerful unions of the publicly owned, vertically integrated monopolistic KOGAS, which objected to the surrender of KOGAS's global natural gas market purchasing capabilities. It is easy to see from this that the natural gas market reform process in all countries in question has been both slow and tortuous, and required tailoring to fit the current political and 


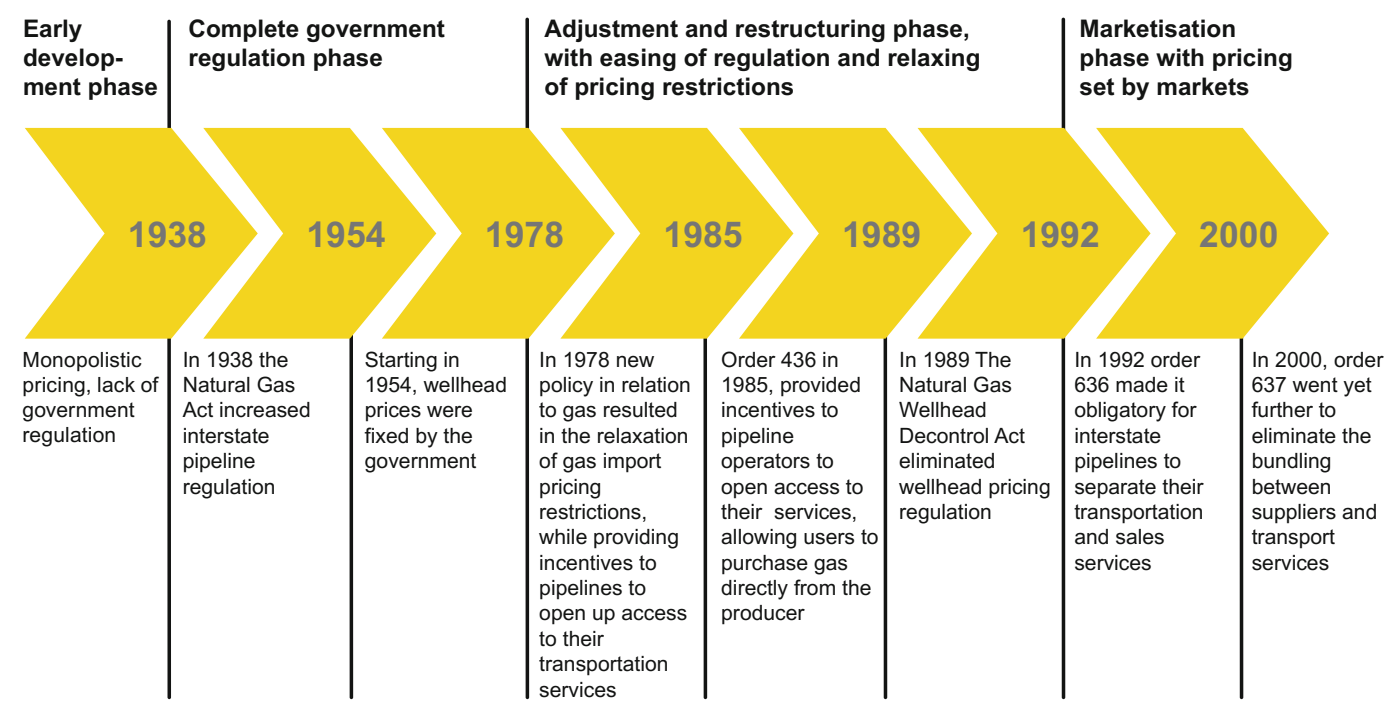

Fig. 12.2 Timeline in the reform of the US natural gas market

economic climate at the same time as implementation of the required policies and measures took place. As such, establishing a roadmap for reform and enforcing its implementation is crucial from the perspective of implementing natural gas market reforms.
Open Access This chapter is licensed under the terms of the Creative Commons Attribution 4.0 International License (http://creativecommons.org/licenses/by/4.0/), which permits use, sharing, adaptation, distribution and reproduction in any medium or format, as long as you give appropriate credit to the original author(s) and the source, provide a link to the Creative Commons license and indicate if changes were made.
The images or other third party material in this chapter are included in the chapter's Creative Commons license, unless indicated otherwise in a credit line to the material. If material is not included in the chapter's Creative Commons license and your intended use is not permitted by statutory regulation or exceeds the permitted use, you will need to obtain permission directly from the copyright holder. 